Revista Signos

$2010 / 43$

Número Especial

Monográfico $\mathrm{N}^{\circ} 2$

343-362

\title{
Dialogicidad y poder en el discurso racista y antirracista
}

\author{
Olga Serradell \\ Universidad Autónoma de Barcelona \\ España
}

\author{
Ariadna Munté \\ Universitat Ramon Llull \\ España
}

\begin{abstract}
Resumen: Los discursos que se generan entre sujetos en situaciones comunicativas reales incluyen, aunque se generen dentro de una relación dialógica, interacciones dialógicas y de poder. Cuando un empresario entrevista a una mujer gitana, musulmana o de un grupo cultural minoritario para un puesto de trabajo, aunque tenga muy buenas intenciones, la relación no es puramente dialógica, pues existen interacciones de poder fruto tanto de la estructura social como de las creencias racistas que se reproducen en el propio lenguaje y experiencia cultural. Nuestra aportación parte de un problema social global como es el racismo para analizar la influencia que tienen los actos comunicativos, tanto en su reproducción como en su superación. Esto nos lleva a estudiar las interacciones de poder que son la base de actos comunicativos racistas como los que se están dando actualmente en Europa. También vamos a identificar la existencia de otro tipo de interacciones, las dialógicas, orientadas al consenso, que son la base de actos comunicativos dialógicos y, por lo tanto, del lenguaje y las prácticas antirracistas.
\end{abstract}

Palabras Clave: Racismo; discurso científico, político, social; comunicación antirracista.

Recibido: 20-IV-2010 Aceptado: 9-VII-2010
Correspondencia: Olga Serradell (olga.serradell@uab.cat). Facultad de Ciencias Políticas y Sociología, Campus de la UAB, Universidad Autónoma de Barcelona. Despacho B3.117-2, 08193, Cerdanyola del Vallès, Barcelona, España. 


\title{
Dialogism and power in racist and antiracist discourse
}

\begin{abstract}
The discourse generated between subjects in real communicative situations includes dialogic interaction and power-related interaction, although it may be generated within a dialogic relationship. When a businessperson interviews a Roma, Muslim or cultural minority woman for a job, even though he or she may have very good intentions, the relationship is not purely dialogic. This is because there is power-related interaction involved, which is the result of the social structure as well as racist beliefs. These are reproduced through people's own language and cultural experiences. In relation to the global social problem of racism, our contribution analyses the impact communicative acts have on both reproducing and overcoming it. This leads to studying the powerrelated interactions that form the basis of racist communicative acts such as those currently taking place in Europe. The existence of other types of interaction will also be identified, such as dialogic interaction, which is consensus-oriented, and forms the basis of dialogic communicative acts and, thereby also anti-racist language and practices.
\end{abstract}

Key Words: Racism; scientific, politic and social discourse; anti-racist communication.

\section{INTRODUCCIÓN}

La orientación teórica desde la cual se analizan los actos comunicativos condiciona enormemente nuestra comprensión sobre el uso que hacemos del lenguaje y sus repercusiones sociales. Autores como Foucault (1971) consideran las relaciones humanas únicamente como relaciones de poder ya que la propia estructura en la que vivimos es desigual. Desde esta perspectiva, el poder es el elemento que domina en todos los actos comunicativos que llevemos a cabo, tanto en la relación que se establece entre una persona gitana y otra que hace de voluntaria para enseñarle a leer y a escribir en un centro educativo; como la que se establece con una que ha participado en ataques contra campamentos de personas gitanas con cócteles molotov. $\mathrm{Si}$ ambas situaciones se analizan como el resultado de la influencia de unos sistemas y estructuras sociales que guían las acciones de los sujetos para mantener un orden social, todo acto comunicativo que se dé en estas relaciones será de poder. Sin embargo, sabemos que entre la persona que está aprendiendo a leer y a escribir y la persona que la ayuda se puede generar solidaridad; mientras que entre la persona agredida y la agresora se genera miedo y conflicto. Ambos efectos son el resultado de actos comunicativos distintos que solamente pueden entenderse si introducimos una perspectiva de análisis dual de la sociedad, que tenga en cuenta ambas dimensiones: sistemas y sujetos.

'Mundo de la vida' y 'sistema' (Habermas, 1987), ‘estructura' y 'agencia' (Giddens, 1991), son algunos de los términos utilizados por las teorías duales más relevantes en ciencias sociales. La agencia humana aglutina un gran número de relaciones que se dan entre sujetos muy distintos. 
Como veremos a lo largo del artículo, cuando estas relaciones se guían por la búsqueda del consenso sin coacciones y la sinceridad, se componen de actos comunicativos e interacciones dialógicas que constituyen el origen de la solidaridad, la amistad, la cooperación o la convivencia intercultural.

La teoría de los actos de habla de Austin, las aportaciones de Searle, el análisis de Habermas en su teoría de la acción comunicativa y la concepción de los actos comunicativos de Soler y CREA (Aubert, Flecha, García, Flecha \& Racionero, 2008), nos acercan a un mayor conocimiento sobre las relaciones, verbales y no verbales, que se dan entre los sujetos, grupos e instituciones en las sociedades actuales. Estas teorías, enmarcadas dentro de la filosofía del lenguaje, aportan elementos clave para analizar y comprender mejor cómo el lenguaje y, de forma más amplia, los actos comunicativos entendidos en el sentido de Soler y CREA, contribuyen a reproducir fenómenos actuales como el racismo.

El análisis dual de la sociedad para el estudio de los actos comunicativos puede, por un lado, ayudarnos a comprender mejor cómo se generan los discursos y acciones racistas. Por otro, puede conducir al desarrollo de acciones preventivas del racismo que sean más eficaces. En el primer apartado del presente artículo nos centramos en la reproducción del racismo a través de los actos comunicativos y las interacciones de poder que son su base. En el segundo veremos cómo es posible desarrollar relaciones más dialógicas que son la base de las prácticas de éxito antirracistas.

\section{La reproducción del racismo a través de los actos comunicativos de poder}

En su análisis del discurso racista, van Dijk (2007) distingue entre el 'dirigido a' los Otros étnicamente diferentes, y el discurso racista 'sobre' los Otros. Del primero se deriva un 'racismo cotidiano', presente en las conversaciones a través de las interacciones verbales que se dan entre los miembros de la comunidad mayoritaria. Ante este discurso, van Dijk (2007) destaca el acoso racista permanente al que se ven sometidos los miembros del grupo étnico minoritario y las implicaciones negativas que tiene para su bienestar y calidad de vida. Un ejemplo serían los actos comunicativos verbales: insultos o comentarios desagradables hacia miembros del grupo étnico minoritario que, por otro lado, serían inaceptables entre los miembros del propio grupo. El racismo sobre los Otros se reproduce a través de las interacciones que se dan en la cotidianidad y en la estructura. Podemos encontrar ejemplos en las instituciones parlamentarias, en los medios de comunicación o en los libros de texto, entre otros ámbitos mayoritariamente controlados por personas de los grupos culturalmente dominantes. Los actos de habla y las interacciones tienen aquí un importante papel. 
Nuestras sociedades son cada vez más diversas en todos los sentidos pero especialmente en el ámbito multicultural. La llegada de personas de diferentes tradiciones, lenguas, y orígenes ha cambiado la estructura social de las sociedades de destino y, así, la composición étnica, religiosa y cultural de su población (Habermas, 2000). La multiculturalidad ha aumentado la diversidad de las interacciones entre personas de distintas culturas y el lenguaje se ha visto también modificado por ella. A pesar de todos estos cambios, la teoría de Austin (1971) sigue teniendo interés por la base que establece para el análisis de los actos de habla, su significado, la intención de los hablantes, los efectos que estos actos tienen y cómo crean realidad.

La realidad se construye socialmente, como Berger y Luckmann (1966) analizaron, y en este proceso el lenguaje tiene un papel especialmente relevante (Austin, 1971). A su vez, el lenguaje viene también establecido desde la estructura, es producto de construcciones previas, históricas, de imágenes estereotipadas sobre determinados grupos culturales como el Pueblo Gitano $u$ otros, que han sido transmitidas a través de la cotidianidad. Si los actos comunicativos que dominan son de poder, estas imágenes del mundo y la forma de plasmarlas con palabras se reproducen. Como veremos en el segundo apartado, al fomentar los actos comunicativos dialógicos se hace posible crear relaciones más dialógicas o bien visibilizar realidades que quedan escondidas por los estereotipos.

Veamos a continuación cómo, a través de los actos comunicativos de poder se reproduce el racismo en los discursos científicos, en la esfera pública y en la cotidianeidad de las personas.

\subsection{En el discurso científico}

Cuando la multiculturalidad se convierte en una característica de nuestras sociedades, la realidad se hace todavía más compleja. Por un lado, las interacciones se hacen más diversas; por otro, los mundos de la vida de los sujetos se ven más frecuentemente cuestionados al interaccionar con personas que tienen perspectivas, creencias y formas de entender el mundo, muy diferentes. Nada puede darse ya por supuesto.

Para describir esta nueva realidad, autores como Huntington (2005) han hablado de 'choque de civilizaciones'. Es un término acuñado desde una perspectiva occidental con fuertes connotaciones etnocéntricas, que implica en sí mismo la falta de consenso y remite a la imposibilidad de llegar a acuerdos entre culturas diferentes. Si tomamos el análisis que hace Flecha (1999) sobre el Racismo Moderno y el Postmoderno ${ }^{1}$ y lo aplicamos al término de Huntington (2005), comprobamos que este contiene rasgos de ambos racismos. El concepto 'choque de civilizaciones' encaja dentro de las características del racismo moderno al plantear la existencia de unas culturas más evolucionadas que otras. Sin embargo, también incorpora elementos del racismo 
postmoderno al proponer una separación de territorios del mundo en civilizaciones basada en unas diferencias culturales y la imposibilidad de diálogo entre ellas. Esta concepción es contraria al giro dialógico de las sociedades teorizado por autores como Flecha, Gómez y Puigvert (2001). En la línea de otras aportaciones de relevancia científica internacional, como la teoría de la acción comunicativa de Habermas (1987), la modernización reflexiva y la desmonopolización del conocimiento experto planteados por Beck, Giddens \& Lash (1997) o la transformación de la modernidad de Touraine (1993), estos autores plantean el paso que están dando las sociedades actuales, donde el diálogo y el consenso, que es fruto del aquel, adquieren mayor relevancia en las relaciones sociales.

Como plantean Aubert et al. (2008), el giro dialógico repercute también en la forma de crear conocimiento científico cuando se da un diálogo con personas 'no expertas'. Sin embargo, siguen dándose relaciones de poder en la creación de este conocimiento. En el ámbito del análisis del lenguaje, la concepción de los actos comunicativos aporta un marco de gran utilidad para profundizar en el tipo de actos e interacciones que sustentan conceptos como el de 'choque de civilizaciones'. Este apela únicamente a las relaciones de poder que se dan entre civilizaciones y presupone que no pueden darse relaciones dialógicas entre ellas. Así, por ejemplo, contrapone Islam a democracia y a esta última la concibe como patrimonio occidental, además de considerar al multiculturalismo como una amenaza para Occidente (Huntington, 2005). Estas afirmaciones han sido fuertemente criticadas por autores como Sen (2007: 165), quien califica a Huntington de "simplificador intelectual" y de "clasificador cultural" y, a su vez, demuestra con múltiples datos históricos que los derechos y libertades individuales han sido promovidas, pero también frenadas, tanto por Occidente como por Oriente.

Este ejemplo muestra que en el proceso de producción de conocimiento científico se dan relaciones de poder, y que estas conviven con la tendencia dialógica de las sociedades y de las ciencias sociales. El diálogo penetra cada día más en las relaciones y actos comunicativos de los individuos, grupos e instituciones, convirtiéndose en su eje vertebrador. Sin una perspectiva dialógica, no puede explicarse la evolución hacia mayores niveles de democracia en todo el mundo. Evidencia de ello es el paso que representa tener que llegar a acuerdos y justificar tales decisiones ante un Parlamento, incluso en el plano supranacional como es el de la Unión Europea (UE). Cada vez más, los gobiernos se ven obligados a argumentar, buscar alianzas y llegar a acuerdos con otros agentes sociales para llevar a cabo cualquier iniciativa política que implique a la ciudadanía. Sin embargo, aunque el diálogo adquiere un papel cada vez mayor, ello no significa que no sigan dándose actos comunicativos de poder en un marco democrático. 


\subsection{En la esfera pública}

Sistemas y sujetos, poder y diálogo, son binomios que conviven en nuestra realidad social. El racismo tiene su base en la desigualdad y se transmite a través de las estructuras sociales (sistemas) y desde los mundos de la vida de las personas (sujetos). Cuando se reproducen discursos racistas, o se llevan a la práctica en forma de acciones violentas contra personas de una minoría étnica, predominan las relaciones de poder donde las interacciones dominantes también son de poder, ya sean entre individuos, grupos o instituciones. Recordemos, por ejemplo, las agresiones de 2008 contra los gitanos en Nápoles. Los agresores llegaron a prender fuego a sus casas en los campamentos donde vivían. Esto ocurría en un clima de fuerte antigitanismo proclamado por la extrema derecha a través de discursos y actos comunicativos de poder. Los medios de comunicación difundieron la noticia de que una menor gitana había intentado secuestrar a una niña. Esto fue utilizado para justificar los ataques hacia toda la comunidad. Hacer pública la etnia de la secuestradora fue un acto comunicativo de poder susceptible de desencadenar la violencia posterior. El clima de antigitanismo que se estaba dando en aquel momento y la constatación de que los gitanos son la minoría étnica más discriminada de Europa (EUMC, 2006), confirman el elevado riesgo de acciones racistas que suponía dar el dato de la etnia, cuando no había justificación alguna para hacerlo. Los efectos de hacer pública esta información fueron el aumento del racismo, que se concretó en agresiones dirigidas a todo un grupo étnico.

La duda que nos puede quedar es la intención de los medios de comunicación, si al dar el dato étnico su intención era simplemente informar o no. Pero independientemente de cuál fuera su intención, el resultado fue un aumento del racismo, algo que solamente puede ser consecuencia de interacciones y actos comunicativos de poder. Las interacciones dialógicas no fomentan el racismo, lo reducen. Ese es un aspecto a tener en cuenta desde los medios dada su responsabilidad social en la creación de opinión. Como explican Chomsky y Herman (1990), muchos periodistas están convencidos de la objetividad de las noticias que elaboran y no pretenden engañar a la población. Sin embargo, además de la intención que tengan los sujetos, es imprescindible tener en cuenta los efectos de sus actos comunicativos. Las pretensiones de validez, son condición necesaria pero no suficiente para que un acto comunicativo sea dialógico. Aunque una persona dedicada al periodismo tenga la intención o la pretensión de decir la verdad cuando da una noticia, no podemos olvidar que se encuentra dentro de una estructura social donde "los medios de comunicación de masas actúan como sistema de transmisión de mensajes y símbolos para el ciudadano medio" (Chomsky \& Herman, 1990: 21). De ahí la relevancia de ir más allá de las intenciones que residen en los actos comunicativos de los sujetos.

En el caso de Nápoles, la culpabilización de toda la comunidad gitana por un acto cometido por una persona caló enormemente en la opinión pública. Esta reacción tiene su origen en los 
fuertes estereotipos contra los gitanos, pero también en el uso que los medios de comunicación y el gobierno hicieron de la situación usando un lenguaje basado en actos comunicativos de poder. Esto ocurría cuando, por ejemplo, los medios hicieron pública la identidad gitana de la chica que secuestró a una niña, suceso a raíz del que se desencadenaron los actos racistas. El ambiente que se generó, favoreció la campaña que el gobierno encabezó contra los gitanos y la inmigración. El gobierno italiano no solo condenó los hechos sino que, además, endureció las medidas contra la inmigración tipificando como delito el hecho de no tener permiso de residencia. Su discurso público se centró en la lucha contra la criminalidad y la búsqueda de la seguridad, dejando entrever que estos dos aspectos se conseguirían si se combatía a la población gitana establecida en Italia en campamentos.

El análisis de los efectos de los actos comunicativos permite identificar el origen de problemas sociales como el racismo o la exclusión. El análisis de las intenciones no. En esta línea, personas gitanas entrevistadas en el proyecto europeo RTD WORKALÓ (CREA-UB, 2001-2004) sacaban a la luz los actos comunicativos de poder realizados por los medios de comunicación al tratar las noticias sobre personas de etnia gitana. Como muestra el ejemplo que sigue, destacaban que cuando una agresión es cometida por una persona gitana se hace pública su etnia, sin embargo, este dato se omite cuando el agresor/a no es gitano:

"Un suceso... una persona ha matado a su mujer, si es de la raza paya ${ }^{2}$, dicen: -un individuo, no sé qué no sé cuántos, ha matado o presuntamente ha matado a su mujer-, pero no dicen de la raza que es, y si ahora lo ha hecho un gitano: -una persona de etnia gitana ha matado a... no sé qué, no sé cuántos-, ¿es verdad o no?" (CREA-UB, 2001-2004).

Al contrario, cuando hay una noticia positiva y la protagoniza una persona gitana, se omite su etnia: “En cambio cuando sale un titular de diario, (...) o sea sale Joaquín Cortés en Nueva York y tal, Joaquín Cortés, ni gitano ni nada, o sea esta es la forma de discriminación"3. Ambos actos comunicativos son de poder porque fomentan estereotipos que vinculan a las personas gitanas con la violencia y la delincuencia. De nuevo, no es la intención sino el efecto de tales actos lo que reproduce o frena el racismo. Omitir la etnia gitana en noticias positivas y hacerla explícita cuando se trata de sucesos violentos o ligados a la delincuencia, son actos comunicativos de poder que se explican por el antigitanismo, ya histórico y fuertemente arraigado, tanto en España como en Europa en general. Los medios de comunicación actuales son fruto de este contexto histórico, han sido creados en un marco racista y han generado estructuras que lo reproducen. Una forma de hacerlo es a través de los actos comunicativos de poder emitidos por los individuos que los integran, los periodistas no gitanos en los ejemplos analizados.

En esta línea, análisis como el de Chomsky ponen el énfasis en que además de divertir, entretener e informar, los medios también cumplen otra función que se consigue a través de 
una 'propaganda sistemática': inculcar valores, creencias y códigos de comportamiento a los individuos que les permitan la integración en la sociedad y, específicamente en sus estructuras institucionales. Nuestra aportación reside en el análisis de las interacciones que dominan dentro de estas estructuras. Si son de poder se reproduce el racismo y la desigualdad. Sin embargo, como veremos en la segunda parte del artículo, fomentando las interacciones dialógicas es posible cuestionar los prejuicios que rigen las interacciones de poder. En los mundos de la vida de los sujetos, en las relaciones que establecen en su día a día, se dan interacciones de poder que son analizados juntamente con la dimensión del sistema de acuerdo con los análisis duales de la sociedad.

\subsection{En la vida cotidiana}

Los ejemplos que siguen se enmarcan en la cotidianeidad. Del mismo modo que el racismo se reproduce a través de estructuras históricamente heredadas, desde los sistemas culturales hasta las instituciones educativas o los medios de comunicación, los mundos de la vida son también fuente de reproducción y creación de estereotipos racistas. Es así como un análisis dual del lenguaje y de los actos comunicativos en general, adquiere especial relevancia para comprender cómo se crea el racismo, pero también cómo y por qué aumenta. La clave se encuentra en el tipo de interacciones.

Imposición o consenso sin coacciones, engaño o sinceridad, son características que nos permiten distinguir cuándo un acto comunicativo es de poder o es dialógico. Diversas investigaciones realizadas con grupos culturales (CREA-UB, 2001-2004; CREA-UB, 2001-2005; CREA-UB, 2005-2009; Sordé, 2007) aportan numerosos ejemplos. En base a algunas de ellas analizamos a continuación algunos de los actos comunicativos que se dieron en situaciones entre personas gitanas y no gitanas. El proyecto WORKALÓ (CREA-UB, 2001-2004) sacó a la luz las consecuencias exclusoras de los estereotipos existentes hacia las personas gitanas, especialmente en el ámbito laboral. Veamos algunas de ellas: "Me dieron las directrices de contratación del personal; lo primero que me dijeron es: ya sabes que nosotros no contratamos nunca ni moros, ni negros ni gitanos".

La persona que expuso esta situación era gitana y la responsable de recursos humanos de la empresa. El mensaje que le dieron sus empleadores fue sincero pero buscaba un efecto exclusor: evitar la contratación de determinadas personas por su etnia o cultura. Esto es el racismo. Así, aunque en la emisión de los empleadores se dé la condición de sinceridad, se trata de un acto comunicativo de poder. No se da la segunda condición para que un acto comunicativo sea dialógico: la búsqueda del consenso sin coacciones. El empleador no busca acordar unos criterios de selección de personal con la persona responsable de recursos humanos pero sí busca 
que la persona esté de acuerdo con la directriz dada y que la cumpla, es decir, da una orden. Para ello hace uso de su posición de poder, es el jefe. Pero además, se añade aquí el hecho que la persona que recibe la directriz de no contratar nunca 'ni a moros, ni negros ni gitanos', es gitana. Así, a una situación de coacción ejercida por los empleadores se le suma una tensión mayor que lleva a la persona gitana a ocultar su identidad étnica. La consecuencia de estos actos comunicativos de poder es una falta de diálogo y de sinceridad, y el fomento de actitudes coaccionantes que engendran interacciones de poder.

Para profundizar en el tipo de coacciones que se dan en los actos comunicativos de poder, analizamos otras situaciones identificadas durante el desarrollo del proyecto WORKALÓ. En una clase de educación secundaria, una profesora dedicó un tiempo de la sesión a preguntar a sus alumnos y alumnas qué carrera querían estudiar. Al llegar el turno a la única alumna gitana, la profesora pasó de largo y no le preguntó. En este caso, dicha omisión es un acto comunicativo basado en los prejuicios que existen hacia las personas gitanas, y especialmente hacia las niñas. La reacción de la niña fue dialógica: pidió a la profesora porqué a ella no le había preguntado. La profesora le dio la palabra para que dijera qué quería estudiar, pero sin responder por qué razón había omitido el testimonio de la niña. Cuando explicó que quería estudiar la carrera de Pedagogía, la profesora le preguntó extrañada, por qué quería abandonar la "bonita tradición del mercadillo"4. Aunque no hubiera 'mala intención' por parte de la profesora, el efecto de este acto comunicativo fue que la niña viera cuestionado su deseo de seguir estudiando pero, además, quien lo cuestionaba era su referente académico, su profesora.

Los actos comunicativos que se dieron generaron interacciones de poder, no deseadas por la niña, y crearon un ambiente coaccionante y de malestar donde se hacía difícil buscar un acuerdo en base a un diálogo igualitario. Así, independientemente de cuál fuera la intención de la profesora, sus actos comunicativos fueron racistas y estuvieron fuertemente influenciados por los estereotipos culturales hacia la comunidad gitana. Los estereotipos se alimentan de actos comunicativos de poder que nos influyen y a través de los cuales reproducimos el racismo. En la situación expuesta, el peso de los estereotipos que tenía la profesora hacia las personas gitanas dificultó que se diera un diálogo libre de coacciones entre ella y su alumna gitana. Primero, la omisión del testimonio de la alumna gitana designa las bajas expectativas académicas que parte del profesorado tiene hacia el alumnado gitano. La posterior respuesta sobre el mercadillo lo corrobora. Pero esta situación no es algo aislado sino que, al contrario, encontramos varios en las investigaciones.

Los ejemplos que siguen son de actos comunicativos de poder que muestran las estrategias que las personas pueden llegar a desarrollar para conseguir un efecto exclusor dirigido a las personas gitanas. En ambos casos son los prejuicios hacia la comunidad gitana lo que guía los actos 
comunicativos. Una persona gitana entrevistada durante la investigación WORKALÓ (CREA-UB, 2001-2004), explicaba que cuando su hermano entró a trabajar en una empresa de aire acondicionado, durante los primeros seis meses los compañeros le dejaban cosas en el taller para ver si las robaba. El prejuicio contra los gitanos guió el acto que pretendía poner a prueba a esta persona. Si hubiera robado, esta acción individual habría sido utilizada como prueba para 'confirmar' el prejuicio existente en la sociedad de que 'los gitanos son unos ladrones'. Todavía hoy, la cuarta acepción del diccionario de la Real Academia Española define "gitano" como "Que estafa u obra con engaño" (Real Academia Española, 2001). Este contexto de antigitanismo condiciona todas las relaciones sociales, entre individuos pero también entre instituciones (escuela, Estado, etc.). Desde el punto de vista de los efectos que genera el acto comunicativo de poder, de poner a prueba la honestidad de una persona por ser gitana, se encuentra el sentimiento de rechazo y falta de confianza. Así, las interacciones que se ven reforzadas son las de poder. Ello genera, a su vez, un clima favorable al conflicto ante cualquier detonante, como pueden ser discursos xenófobos de los medios de comunicación o de los partidos políticos, entre otros.

El último ejemplo se sitúa en el ámbito educativo y permite profundizar en los efectos exclusores de las múltiples interacciones de poder dadas. Un padre gitano fue a inscribir a su hijo de 12 años a un Instituto de Educación Secundaria. Cuando pidió plaza para el chico, la dirección le respondió que no quedaban, lo cual no era verdad. En este proceso hay implícitos múltiples actos comunicativos en los que intervienen otros agentes e interacciones, tales como las imágenes fomentadas por los medios de comunicación sobre la comunidad gitana, las conversaciones y comentarios sobre los gitanos con el resto de profesorado, en reuniones familiares o con grupos de amigos. El lenguaje establecido por el profesor con otros compañeros o familiares, crea realidad y refuerza una idea de los gitanos que le conduce a dar una respuesta falsa al padre gitano. Ya sea de forma activa, participando en conversaciones donde se estigmatiza a las personas gitanas, o de forma pasiva, escuchando noticias donde se culpabiliza a todos los gitanos de determinados actos (delitos, faltas) cometidos por uno de sus miembros, el director del centro había desarrollado una imagen estereotipada de las personas gitanas. Esta imagen está generada por un lenguaje que no es dialógico sino de poder.

Ya ha ocurrido en otras ocasiones, que ante la entrada de alumnado gitano en centros educativos, las familias no gitanas han sacado a sus hijos del centro. La decisión del director de mentir respecto a las plazas tenía como objetivo evitar la entrada de un alumno gitano por un racismo que se refleja en su miedo a la reacción de las familias no gitanas y del propio profesorado. Respecto al padre gitano, este ve en la institución escolar un rechazo a su hijo y a su comunidad, hecho que explicará a sus familiares y que puede desanimar a las familias gitanas a fomentar las trayectorias académicas de sus hijos e hijas. Pero también está el niño, lo que tal rechazo 
representa para él y cómo influye en las expectativas que crea sobre sí mismo. En este caso el director del centro usó su posición de poder para evitar la entrada de un niño gitano en su centro. Si su intención hubiera sido garantizar el derecho a la educación del niño gitano, habría manifestado de forma sincera su miedo al desprestigio del centro o a que las familias no gitanas sacaran a sus hijos. En este caso, las pretensiones de validez habrían sustituido a las de poder creándose las condiciones necesarias para que se dé un diálogo orientado a encontrar formas de garantizar tal derecho. Solo así habría sido posible cambiar los efectos exclusores del acto comunicativo del profesor.

En esta línea, en el siguiente apartado analizamos ejemplos basados en actos comunicativos e interacciones dialógicas, características de las prácticas y actuaciones de éxito que superan el racismo.

\section{La superación del racismo a través de los actos comunicativos dialógicos}

La realidad es más compleja de lo que cualquier categoría de análisis o 'tipo ideal' pueda reflejar. Por ello, es muy relevante conocer los elementos que indican si una relación entre dos personas es más o menos dialógica, si tiende a la búsqueda del consenso, o bien si está únicamente basada en la relación de poder mediada por el ejercicio de la autoridad de una de las partes; si se hacen explícitos argumentos de forma sincera, o por el contrario, si se miente o se omite información relevante para el interlocutor. En el apartado anterior hemos visto ejemplos de situaciones en las que dominan las interacciones de poder en los actos comunicativos. Esta parte la centramos en analizar el tipo relaciones y de actos comunicativos que predominan en las actuaciones de éxito, es decir, las que fomentan la igualdad y reducen el racismo.

Cuando el diálogo adquiere mayor importancia en las relaciones sociales, las posibilidades de combatir los discursos racistas son mayores. En el siglo XIX, los teóricos de la democracia consideraban que para tenerla, un país debía estar 'maduro'. De acuerdo con Sen (2007) esa no es la cuestión. Durante el siglo XX se da un giro en la perspectiva y se plantea la cuestión argumentando que un país no está 'maduro' para la democracia sino que llega a la madurez a través de la democracia, lo que otorga al diálogo un papel esencial. Este es un ejemplo más del giro dialógico que están dando las sociedades y también las ciencias sociales.

La extensión de la democracia en una gran cantidad de países a lo largo del siglo XX demuestra que, cada día más, el diálogo penetra en las relaciones entre individuos y también en las instituciones generando estructuras más igualitarias. Sin embargo, una de las aportaciones más interesantes de la concepción de los actos comunicativos es que, aunque las relaciones 
dialógicas vayan ganado protagonismo, se dan también relaciones de poder en los sistemas democráticos, como hemos visto a través del ejemplo del papel de los medios de comunicación en la promoción del racismo.

\subsection{Democracia y actos comunicativos de poder: El poder de las interacciones dialógicas}

Podemos entender la democracia a partir de la concepción de los actos comunicativos, como un conjunto de relaciones dialógicas entre grupos, instituciones e individuos en las que predominan los actos comunicativos dialógicos pero en las que también se dan, en menor medida, actos comunicativos de poder. Eso explica, por ejemplo, que exista racismo en sociedades democráticas. Tanto las estructuras como en algunos casos la agencia humana (y los estereotipos culturales que de estas se derivan) reproducen el racismo: desde las instituciones políticas, los medios de comunicación, los centros educativos, etc.

Un discurso frecuente que fomenta tales estereotipos es la falsa vinculación que se establece entre las personas inmigrantes o gitanas por un lado, y conflicto, delincuencia e inseguridad por otro. Todos los actos comunicativos que se realizan en esta dirección (desde los titulares de los periódicos, hasta las intervenciones del gobierno o la opinión manifestada por el equipo docente de una escuela), no solamente son un grave error científico sino también ético. Como ya han señalado Mircea y Sordé (en proceso) la mejora de la convivencia y el éxito social de las personas gitanas o inmigrantes depende de las actuaciones políticas, sociales y educativas que se lleven a cabo y no de la proporción de personas gitanas o inmigrantes que haya en un país, en un barrio, en una escuela o en un aula.

No podemos obviar en nuestro análisis que Europa se encuentra en estos momentos inmersa en una creciente ola de racismo paralela a la crisis económica global. Aún así, el marco democrático de la UE posibilita que se den más interacciones dialógicas o, como muestra el siguiente ejemplo, que estas se den incluso en un contexto donde predominan las interacciones de poder. La intervención de una mujer gitana, Radics Hajnalka, en el mitin de Gábor Vona, líder del partido Jobbik de extrema derecha en Hungría, a principios de abril de 2010 es un claro ejemplo de la importancia de contar con un contexto democrático para combatir el racismo manifestado a través de actos comunicativos de poder. Esta mujer de 47 años, jornalera de la recogida de la uva, era la única gitana entre los 200 asistentes al mitin. El discurso racista de Vona era explícitamente antigitano y culpaba a esta comunidad de los altos niveles de paro del país. Esta mujer se levantó para decir: “¿Qué pasa? Yo nací aquí y trabajo como el resto”. Realizó esta intervención en un contexto que dificultaba el diálogo, existían coacciones. Pero aún así, la hizo porque Europa es democrática, como ella misma explicó. En este caso, la estructura posibilitaba que se pudiera dar un acto comunicativo en un contexto donde la agencia humana (los 
seguidores de Gábor) pretende imponer interacciones de poder. Fue justamente la garantía que representan instituciones democráticas como la UE y su voluntad como entidad supranacional, lo que le dio fuerzas para hacer oír sus argumentos: "No tengo miedo porque la Unión Europea no permitirá jamás que haya otro Auschwitz, ¿verdad?” (Robinson, 2010).

Su intervención fue sincera y superó las coacciones que interferían. Su acto comunicativo estuvo basado en la libertad de expresión que le concede el marco democrático de la UE, más dialógico que cualquier Estado dictatorial. Solamente en un marco tal es posible una intervención como la de Radics: la interacción que creó con los 200 asistentes y con el líder de extrema derecha cuestionaba las afirmaciones antigitanas. Este ejemplo muestra que en nuestra sociedad conviven interacciones de poder e interacciones dialógicas. La cuestión es cómo crear los contextos favorables para que dominen las segundas sobre las primeras.

\subsection{Prácticas de éxito: Diálogo igualitario y multicultural}

La democracia es un logro de la humanidad y no de una cultura determinada. Es, por lo tanto, fruto de actos comunicativos dialógicos formados por una multiplicidad de interacciones entre una gran diversidad de grupos y personas. Así, las interacciones dialógicas entre culturas incrementan la democracia puesto que llevan a consensos que rigen las relaciones futuras, a menudo plasmados en forma de normas, entre las personas y las organizaciones que las representan.

Ya sea desde la esfera privada de la familia o en una campaña electoral, los actos comunicativos que desarrollamos a través de nuestras interacciones crean realidad. Del mismo modo, cuando en el lenguaje dominan relaciones de poder manifestados en forma de prejuicios y estereotipos, los propios actos pueden camuflar la realidad o invisibilizarla como muestra el ejemplo siguiente extraído de una investigación realizada con población inmigrante.

Uno de los objetivos del proyecto TRANSMIGRA (CREA-UB, 2005-2009) era estudiar las actividades económicas transnacionales que las mujeres marroquíes, ecuatorianas y rumanas estaban realizando entre sus países de origen y España. En la entrevista a uno de los responsables del polo económico de la Fundación Hasan II de Marruecos, este respondía que en Marruecos todavía no había mujeres marroquíes que estuvieran creando empresas. Este acto comunicativo estaba basado en la sinceridad, puesto que los datos con los que él contaba no permitían afirmar otra cosa. Aún así, la comunidad científica ha mostrado que los estereotipos de género son universales, se encuentran en todas las sociedades y afectan a los discursos que en ellas se producen, del mismo modo que lo hacen los estereotipos racistas. El entrevistado, como cualquier otra persona, no escapa a tal influencia y sus actos comunicativos deben ser analizados teniendo en cuenta este posible sesgo. 
Las interacciones que nosotros manteníamos con personas marroquíes residentes en España, nos llevaban a pensar que la de las mujeres empresarias marroquíes era una realidad que existía pero que estaba invisibilizada. Esta hipótesis era fruto de interacciones dialógicas que nos proporcionaba nuestra vinculación con entidades en las que participan activamente mujeres inmigrantes, así como el trabajo de campo realizado en España y Francia con mujeres marroquíes y de otras nacionalidades que gestionan sus propios negocios, que son miembros activos, e incluso fundadoras, de asociaciones. En definitiva, mujeres con sus propios proyectos personales y profesionales. Con el objetivo de conocer más sobre los proyectos económicos de estas mujeres, entrevistamos a diferentes personas entre las cuales, una profesora de instituto, representante del Foro de mujeres de Larache (Marruecos) y que era también voluntaria en una asociación de formación profesional para mujeres. Ante la misma pregunta sobre si conocía a mujeres empresarias, su respuesta fue negativa al principio. Los estereotipos de género no afectan solamente a los hombres de una determinada cultura sino que, como hemos dicho, son universales, los tienen hombres y mujeres de diferentes culturas y religiones, puesto que forman parte de una estructura patriarcal de valores que nos han sido transmitidos históricamente, a lo largo de generaciones. Aquella mujer, marroquí, formada, activista social y solidaria con otras mujeres también estaba influida por el discurso dominante basado en estereotipos y, por lo tanto, en actos comunicativos de poder que presuponen a la mujer marroquí la pasividad y la incapacidad de llevar a cabo proyectos empresariales propios.

La visita a la asociación de formación profesional donde colaboraba la mujer marroquí entrevistada, generó nuevas interacciones que nos permitieron profundizar en el análisis de aquella realidad. A medida que avanzábamos en el diálogo, descubríamos el potencial de la entidad y de las mujeres que se formaban en los talleres de peluquería y confección, entre otros. Entonces fue cuando ella misma puso palabras a una realidad que ya existía:

"Yo conozco a una chica que trabaja con nosotros en la asociación que ha hecho una formación en la asociación, de peluquería, y después ha creado un taller de peluquería y su hermano que está en España es el que le da dinero para hacerlo, para hacer el proyecto (...) [Su hermano] le dijo que cuando viniera en verano se podía comprar una casa y habilitar una parte para hacer la peluquería, un local (...). La peluquería se llama Libertad”5.

En este caso, gracias al diálogo libre de coacciones y a la validez de los argumentos aportados, salió a la luz una realidad que rompía estereotipos históricos sobre la mujer musulmana, rompiendo con la idea inicial de que esta realidad no existía y creando nuevo conocimiento. Vemos pues cómo a través de los propios actos comunicativos también se pueden crear y visibilizar nuevas realidades. Como analizaron Berger y Luckmann (1966) desde las teorías del sujeto, la capacidad de crear nuevas realidades está unida a la capacidad de lenguaje y acción de los 
sujetos y de interpretación de la propia realidad. Un ejemplo más lo refleja.

En unas jornadas estatales de educación de personas adultas (CONFAPEA, 2010) una chica marroquí, musulmana, con velo y de 21 años, explicó vía Skype su experiencia como colaboradora en una actividad de formación de familiares de una escuela, en la que participan otras mujeres, algunas de ellas marroquíes y semianalfabetas. Su intervención iba dirigida a un público diverso en el que había profesorado universitario, educadores/as y maestros/as de educación de personas adultas y personas participantes en procesos de formación. En su exposición virtual se dieron una gran cantidad de actos comunicativos, verbales y no verbales. El propio uso del velo es uno de ellos. Este generó una nueva interacción puesto que iba unido a una interesante explicación sobre la lectura y el debate que las madres marroquíes estaban teniendo alrededor de una obra clásica de la literatura universal, 'La casa de Bernarda Alba' de Federico García Lorca. Esta interacción fue nueva para muchas de las personas asistentes a la jornada porque, hasta entonces, vinculaban el velo islámico a un estereotipo de mujer, sumisa, apática y con pocas o ninguna inquietud literaria o personal. Este debate literario que fomenta las interacciones dialógicas en detrimento de las de poder es una práctica de éxito que combate el racismo.

Es interesante analizar algunos de los actos comunicativos que pueden darse hasta llegar a una actuación tal. En ella no podemos olvidar la posición de 'mayor poder' que ocupan actores sociales como el profesorado. Este tiene mayor capacidad de intervención en los procesos de decisión sobre las actividades educativas. Así, por un lado, si la relación de poder existente entre profesorado y familiares marroquíes es la base de los actos comunicativos una actividad tal no puede darse. Por otro lado está la confianza que el profesorado confiere a estas mujeres y su capacidad de leer y debatir esta obra clásica. Estas bajas expectativas son también actos comunicativos que se transmiten, a menudo sin mala intención, a las propias mujeres, al resto de profesorado, al alumnado, etc., generando interacciones que no favorecen la superación de los estereotipos existentes hacia la mujer musulmana. Aquí es donde la concepción de los actos comunicativos aporta un concepto fundamental para comprender los procesos de comunicación: las interacciones dialógicas. Una de las colaboradoras en la actividad de formación de familiares tenía dudas de que pudiera funcionar una 'tertulia literaria' (ver artículo de Pulido \& Zepa en este monográfico) con las participantes sobre una obra como la de García Lorca. Sin embargo, en esta escuela predominan las interacciones dialógicas entre profesorado, colaboradores, alumnado, familiares y otros agentes de la comunidad educativa. Este contexto, unido a la predisposición al diálogo de la colaboradora, permitió que esta decidiera llevar adelante la propuesta de realizar la actividad de lectura dialógica sobre una obra de la literatura clásica universal con mujeres marroquíes y semianalfabetas. 
Como muestra este ejemplo, es posible sustituir los actos comunicativos de poder por actos comunicativos dialógicos. Una de las condiciones que debe darse es la sinceridad. Las dudas que transmite la colaboradora sobre la posibilidad de que funcione la actividad son fruto de los prejuicios existentes en nuestra sociedad. Pero el hecho de ser sincera y exponer estas dudas es lo que hace que la interacción sea dialógica. La búsqueda del acuerdo es la segunda característica de los actos comunicativos dialógicos. El consenso implica algo nuevo, que se construye entre todas las personas y, por lo tanto, imposible de lograr de forma individual. La clave del consenso reside en la interacción de la que derivan acciones como la que acabamos de describir.

\section{CONCLUSIONES}

Cuánto más diversas sean nuestras interacciones, mayor será la posibilidad de tener referentes distintos que contrarresten los efectos de los actos comunicativos de poder. Las interacciones homogéneas generan discursos e imágenes del mundo estereotipadas que no responden a la realidad multicultural. Cuando predominan las interacciones de poder, tales estereotipos recaen sobre los grupos más vulnerables como las personas gitanas o inmigrantes. Cuando predominan las dialógicas se da un mejor aprovechamiento de la diversidad cultural, favoreciendo la heterogeneidad en nuestras interacciones, creando nuevos referentes y muy distintos entre ellos y reduciendo, así, el riesgo de caer en imágenes estereotipadas. Estas interacciones son el corazón de nuestros actos comunicativos. Los de poder fomentan discursos racistas y xenófobos, generan efectos exclusores que perjudican a grupos culturales minoritarios como el Pueblo Gitano, y podemos encontrarlos en muy diferentes ámbitos de la sociedad: en los discursos científicos, en los medios de comunicación o en cualquier situación de nuestra vida cotidiana.

Desde conceptos teóricos como el de 'choque de civilizaciones', lemas políticos reaccionarios o a través de un uso irresponsable del lenguaje por parte de los medios de comunicación cuando establecen falsas vinculaciones entre etnia y delincuencia, se generan discursos racistas que calan en la sociedad y penetran en los actos comunicativos que establecen las personas en su día a día. Pero lejos de aceptar que todas las relaciones e interacciones son de poder y que no se puede hacer nada para evitarlo, la concepción de los actos comunicativos dialógicos contempla el concepto de interacción dialógica para identificar un lenguaje caracterizado por la sinceridad y la búsqueda del consenso sin coacciones. Al introducir este concepto al análisis del lenguaje y de los discursos racistas, identificamos que no todas las relaciones son de poder y que es posible llegar a acuerdos entre personas de diferentes culturas e incluso crear relaciones de solidaridad entre ellas. 
Así, la democracia es un marco que hace posible, más que cualquier otro, el desarrollo de actos comunicativos dialógicos. Sin embargo, en este contexto también se dan actos comunicativos de poder. Los lemas xenófobos apelan a derechos universales, como la igualdad de género o la no discriminación conseguidos gracias a las luchas de movimientos igualitarios, para usarlos en contra de la igualdad de derechos de todas las personas. Estos discursos se sirven de las estructuras del sistema democrático para restringir los derechos a los miembros de determinados grupos culturales como el Pueblo Gitano o la comunidad arabo-musulmana. De la misma forma que es posible un análisis crítico del discurso racista que se encuentra en los lemas de los partidos xenófobos, también los actos comunicativos requieren ser sometidos a una crítica sobre la posición de poder desde la que son realizados y el uso que hacen del lenguaje. Es el caso de los empleadores que no quieren contratar a gitanos o de los profesores que no quieren alumnos inmigrantes en sus centros educativos. Tales actos comunicativos tienen como efecto la exclusión de personas de un determinado grupo cultural minoritario. Esto es racismo.

En esta línea, la distinción entre racismo moderno y postmoderno nos permite ir más allá e identificar el importante papel que juega la violencia simbólica del uso del lenguaje que hace el discurso racista postmoderno. Para este último las relaciones sociales siempre son de poder. Ante un discurso 'antirracista' de respeto a la diferencia, se difama a grupos como el gitano para justificar su expulsión o segregación. La concepción de la diferencia que reside en tales discursos y actos no es igualitaria, sino que niega la posibilidad de diálogo entre culturas, la existencia de valores universales o la posibilidad de crear nuevas realidades y relaciones de solidaridad a partir del lenguaje y las interacciones dialógicas. El análisis de las interacciones y los actos comunicativos que constituyen el discurso racista postmoderno permite, por un lado, comprender cómo se reproducen los estereotipos en las estructuras y en mundos de la vida de los sujetos; por otro, identificar discursos y actos comunicativos racistas, incluso cuando estos se definen como 'antirracistas' o apelan a los derechos democráticos.

La democracia aporta estructuras más igualitarias para la sociedad que las de cualquier gobierno totalitario. En ella conviven actos comunicativos dialógicos y de poder. Sin embargo, la posibilidad de que las primeras aumenten en detrimento de las segundas solamente es posible en un marco institucional donde predominen las relaciones dialógicas. A su vez, los actos comunicativos dialógicos refuerzan las estructuras igualitarias de nuestras sociedades. Las interacciones dialógicas crean nuevas imágenes y realidades del mundo y de las personas gitanas o inmigrantes. Pero también permiten visibilizar realidades que ya existen y, a través de un diálogo igualitario y libre de coacciones, ampliar el conocimiento sobre las mismas. Esto es posible cuando las pretensiones de validez, la sinceridad y la búsqueda del consenso sin coacciones guían los actos comunicativos y las interacciones entre los sujetos participantes. 
En definitiva, podemos afirmar que las actuaciones de éxito fomentan las interacciones dialógicas entre personas de diferentes culturas y en diferentes espacios o contextos. Cuando estas se multiplican, los actos comunicativos que producen son más dialógicos y hacen posible romper las imágenes estereotipadas (basadas en actos comunicativos de poder) sobre las personas gitanas y arabo-musulmanas, entre otros grupos culturales. El análisis del poder y del diálogo que incluye la concepción de los actos comunicativos es el elemento que permite avanzar en el conocimiento del lenguaje y tener en cuenta condicionantes tales como los prejuicios racistas, las posiciones de poder y el uso que de ellas hacen. Pero sin olvidar que son determinadas actuaciones las que fomentan los actos comunicativos dialógicos y permiten que, cada vez más, las interacciones dialógicas sustituyan a las de poder.

\section{REFERENCIAS BIBLIOGRÁFICAS}

Aubert, A., Flecha, A., García, C., Flecha, R. \& Racionero, S. (2008). Aprendizaje dialógico en la sociedad de la información. Barcelona: Hipatia.

Austin, J. L. (1971). Cómo hacer cosas con palabras. Buenos Aires: Paidós.

Beck, U., Giddens, A. \& Lash, S. (1997). Modernización reflexiva. Política, tradición y estética en el orden social moderno. Madrid: Alianza.

Berger, P. \& Luckmann, T. (1966). La construcción social de la realidad. Buenos Aires: Amorrotu.

Chomsky, N. \& Herman, E. S. (1990). Los guardianes de la libertad. Propaganda, desinformación y consenso en los medios de comunicación de masas. Barcelona: HUROPE.

CONFAPEA. (2010). IV Trijornadas en Educación Democrática de personas Adultas. Formación de familiares, excelencia y democracia [en línea]. Disponible en: http://trijor.wordpress.com/

CREA-UB. (2001-2004). WORKALÓ Project. The creation of new occupational patterns for cultural minorities: The gypsy case. FP5, European Comission RTD.

CREA-UB. (2001-2005). AMAL: Inmigración y mercado laboral. Plan Nacional I+D. Ministerio de Ciencia y Tecnología.

CREA-UB. (2005-2009). TRANSMIGRA. Análisis de los procesos de transnacionalidad económica y política marroquí, ecuatoriana y rumana. La inmigración como factor de desarrollo en los países de origen y acogida. Plan Nacional I+D. Ministerio de Ciencia e Innovación.

EUMC (European Monitoring Centre on Racism and Xenophobia). (2006). Annual report 2006. EUMC [en línea]. Disponible en: http://fra.europa.eu/fraWebsite/products/publications_reports/annual_report/ar2006_part2_en.htm 
Flecha, R. (1999). Modern and Postmodern Racism in Europe: Dialogic Approach and Anti-racist Pedagogies. Harvard Educational Review, 69(2), 150-171.

Flecha, R. \& Gómez, J. (1995). Racismo: No, gracias. Ni moderno, ni postmoderno. Barcelona: El Roure.

Flecha, R., Gómez, J. \& Puigvert, L. (2001). Teoría sociológica contemporánea. Barcelona: Paidós.

Foucault, M. (1971). Las palabras y las cosas. Madrid: Siglo XXI.

Giddens, A. (1991). Modernity and self-identity. Self and society in the late modern age. Cambridge: Polity- Press.

Habermas, J. (1987). La teoría de la acción comunicativa. I: Racionalidad de la acción y racionalización social; II: Crítica de la razón funcionalista. Madrid: Taurus.

Habermas, J. (2000). La constelación posnacional. Ensayos políticos. Barcelona: Paidós.

Huntington, S. P. (2005). El choque de civilizaciones y la reconfiguración del orden mundial. Barcelona: Paidós.

Mircea, T. \& Sordé, T. (en proceso). How to turn difficulties into opportunities: Drawing from diversity to promote social cohesion. International Studies in Sociology of Education.

Real Academia Española. (2001). Diccionario de la lengua española. Vigésima segunda edición [en línea]. Diponible en: http://buscon.rae.es/drael/SrvltConsulta?TIPO_ BUS $=3 \& L E M A=$ gitano

Robinson, A. (2010). La extrema derecha puede convertirse en la tercera fuerza política en las legislativas. La Vanguardia [en línea]. Disponible en: http://www.lavanguardia.es/internacional/noticias/20100411/53904531306/la-extrema-derecha-puede-convertirseen-la-tercera-fuerza-politica-en-las-legislativas-budapest-ausc.html

Sen, A. (2006). La démocratie des autres. Paris: Payot \& Rivages.

Sen, A. (2007). India contemporánea: Entre la modernidad y la tradición. Barcelona: Gedisa.

Sordé, T. (2007). Quitarse de la escuela. Persistence and dropping out among Romani girls. Unpublished Tesis Faculty of the graduate school of education of Harvard University, USA.

Touraine, A. (1993). Crítica de la modernidad. Madrid: Temas de Hoy.

van Dijk, T. (2007). Prólogo. Discurso racista. En J. J. Igartua \& C. Múñiz (Eds.), Medios de comunicación y sociedad (pp. 9-16). Salamanca: Ediciones Universidad de Salamanca.

\section{NOTAS}

1 Los conceptos de racismo moderno y racismo postmoderno fueron acuñados por Flecha y Gómez (1995) ante la necesidad de destacar los cambios que se estaban dando en los discursos racistas, científicos, políticos y sociales, especialmente a partir de los años 80 . Así, mientras el primero se basa en conceptos como raza, subordinación y nazismo; el racismo postmoderno incorpora un 
concepto de 'diferencia' unido al territorio y a un nazismo que se autodefine como 'anti-racista' (Flecha, 1999). Ambos racismos se basan en interacciones de poder que producen actos comunicativos cuyos efectos incrementan la discriminación de grupos culturales minoritarios como el Pueblo Gitano.

2 Payo/a es un término utilizado por las personas gitanas para designar a las personas no gitanas, la comunidad mayoritaria en España.

3 Información recogida a través del trabajo de campo realizado en el marco del proyecto RTD, del V Programa Marco de la Comisión Europea, WORKALÓ (CREA-UB, 2001-2004).

4 El 'mercadillo' es una actividad laboral ligada a la venta ambulante. Caracterizada por la inestabilidad y precariedad laborales, se trata de ocupaciones de baja cualificación a las que se ha dedicado tradicionalmente una parte de la población gitana en España.

5 Información recogida a través del trabajo de campo realizado en el marco del proyecto del Plan Nacional I+D del MICINN, TRANSMIGRA (CREA-UB, 2005-2009). 